\title{
Results of Excision of Unknown Papillary Neoplasms Detected on Core Biopsy
}

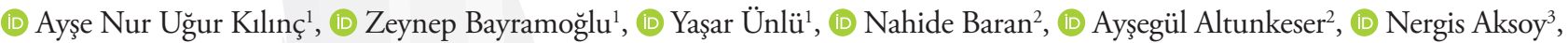
(1) Mehmet Ali Eryılmaz ${ }^{3}$, (1) Elif Nur Öztürk Yıldırım

${ }^{1}$ Department of Pathology, Konya Training and Research Hospital, Konya, Turkey

${ }^{2}$ Department of Radiology, Konya Training and Research Hospital, Konya, Turkey

${ }^{3}$ Department of General Surgery, Konya Training and Research Hospital, Konya, Turkey

${ }^{4}$ Department of Public Health, Konya Akşehir Health Management, Konya, Turkey

\section{ABSTRACT}

Objective: This study aimed to find out valuable parameters that predict the nature of breast papillary lesions before excision, and we compared our results with those in the literature.

Materials and Methods: We reviewed the medical records and pathology slides of patients diagnosed with papillary neoplasm after undergoing a coreneedle biopsy between 2010 and 2020, who, subsequently, underwent surgical excision in a single tertiary care institution. The core biopsy results and pathology results of excision materials were compared with the radiological, pathological, and demographic findings.

Results: A total of 51 patients were included in the study. According to the excision results, the patients were divided into two groups: the atypical group, which included 20 patients (39.3\%), and the benign group, which included 31 patients (61.7\%). The results of the core biopsy showed that the loss of myoepithelial cell layer was identified in 18 patients in the atypical group, while it was present in all patients in the benign group. Tumor sizes were larger and patient ages were older in the atypical group compared with the benign group. No significant difference was found between atypical and benign groups in terms of breast imaging-reporting and data system (BI-RADS) classification and location (right vs left; central vs peripheral). The upgrade rate was between $0 \%$ and $16 \%$ in literature, while it was $4 \%$ in our study.

Conclusion: There is no consensus on whether patients diagnosed with papillary neoplasia as a result of core biopsy will undergo excision. According to our results, patients with following criteria should have their lesions excised: those who are advanced in age, those who are diagnosed with a papillary lesion as a result of core biopsies with loss of myoepithelial cell layer, and those who are diagnosed with large-sized lesions without loss of myoepithelial cell layer. Patients diagnosed with small-sized lesions without loss of myoepithelial cell layer and who are young in age are to be followed up without the need for lesion excision. The lesions should be adequately sampled.

Keywords: Breast neoplasm, core biopsy, papillary neoplasm

Cite this article as: Uğur Kılınç AN, Bayramoğlu Z, Ünlü Y, Baran N, Altunkeser A, Aksoy N, Eryılmaz MA, Öztürk Yıldırım EN. Results of Excision of Unknown Papillary Neoplasms Detected on Core Biopsy. Eur J Breast Health 2021; 17(3): 258-264

\section{Key Points}

- In particular, there is no consensus on whether patients with a diagnosis of papillary neoplasia resulting from core biopsy will undergo excision.

- According to the results of our study, patients with advanced age, a diagnosis of papillary lesions as a result of core biopsy with loss of myoepithelial layer, and large-sized lesions should have their lesions excised.

- In patients who did not experience loss of myoepithelium, it should be ensured that it is adequately sampled if the lesion will not be excised.

\section{Introduction}

Papillary breast neoplasms are lesions with a fibrovascular core surrounded by an epithelial cell layer. Most of the papillary lesions are restricted to cystically dilated ducts and have thick fibrous walls. Intraductal papillary neoplasms of the breast are intraductal papilloma with atypical ductal hyperplasia/ductal carcinoma in situ (DCIS), papillary DCIS, and solid and encapsulated papillary carcinomas in situ. Papillary lesions of the breast span the spectrum of benign, atypical, and malignant. While the myoepithelial cell layer reveals continuity in all benign intraductal 
papillary neoplasmas, the type of the lesion in atypical papillary lesions varies according to the presence of the myoepithelial cell layer inside and around the papilla (1).

In all breast lesions, core biopsies can efficiently predict the nature of the lesion. In papillary lesions, histopathological assessment of core biopsies is very effective when deciding on excision or follow-up of the lesion. However, in some papillary lesions, the nonhomogeneity of the lesion decreases the reliability of core biopsy (1).

In our study, we included patients who were diagnosed with papillary neoplasm as a result of core biopsies done at our hospital and whose excision materials were present in our hospital, but the type of their lesions could not be specified. The demographic, radiological, and histopathological characteristics of the patients were analyzed. We aimed to find out valuable parameters for predicting the nature of breast papillary lesions before excision and compared our results with those in the literature.

\section{Materials and Methods}

The pathological data of patients who were diagnosed with papillary neoplasia as a result of core-needle biopsies done at our hospital between 2010 and 2020 and whose excision materials were present in our hospital were assessed. The radiological images and pathological slides of all patients were reassessed.

The excision results of patients were classified according to the International Classification of Diseases for Oncology, Third Edition, Second Revision (ICD-O-3.2) determined by WHO. Papillary lesions are classified as benign, malignant, or uncertain behavior lesions according to ICD-O-3.2 (1). We divided them into two groups: the atypical group, which included the malignant and uncertain behavior lesions, and benign group, which included the benign lesions (1).

Radiological parameters such as ductal ectasia, microcalcification, mean size of the lesion, peripheral or central location of the lesion, and BI-RADS category, pathological parameters, such as immunohistochemical markers, and demographic data were analyzed in selected patients. At least two myoepithelial markers, one cytoplasmic and the other nuclear [high molecular weighted cytokeratin (HMWCK), SMA, CK5/6, CK14, and p63], were routinely used in all core biopsy specimens and excision materials. In addition to these, the estrogen receptor was investigated in patients when necessary.

There were less than six months between durations of excision materials and core biopsy of patients included in the study.

Patients whose excision was not performed at our hospital and patients whose final diagnosis and classification were identified using core biopsy materials were excluded from our study.

We compared between the atypical papillary lesion and benign papillary lesion groups. We used the Statistical Package for Social Sciences version 21 (IBM SPSS Corp; Armonk, NY, USA) for statistical analysis. The results of categorical variables are shown in tables and charts where appropriate. Differences between groups were determined using the Mann-Whitney $U$ test for numerical variables. Categorical variables were determined using the chi-square test. $\mathrm{p}<0.05$ was considered statistically significant.

\section{Results}

Fifty-one patients were included in the study: 31 in the benign group and 20 in the atypical group (Table 1). Excision diagnoses of the 51 patients with papillary neoplasm are shown in Table 2.

The median age of the patients included in the study was 44 (24-79). $90 \%$ of the patients were older than 40 years. The mean age was 59.4 (40-79) in the atypical group and $48(23-70)$ in the benign group (Table 1).

The mean size of the largest tumor detected on ultrasound was $14.2 \pm 0.9 \mathrm{~mm}$ in the benign group and $31.15 \pm 1.2 \mathrm{~mm}$ in the atypical group (Table 1).

Papillary lesions were observed more on the left $(61 \%)$ than on the right (39\%). However, no significant difference was found between the atypical and benign groups in terms of lesion laterality $(p>0.01)$.

Five of the patients underwent only ultrasonography (USG), four underwent USG and magnetic resonance imaging (MRI), 21 underwent USG and mammography (MMG), and 20 patients underwent all three imaging methods.

According to ultrasonographic locations, lesions of only three patients $(10 \%)$ in the benign group were located in the peripheral ducts and the rest of the patients $(28 ; 90 \%)$ had centrally located lesions. In the atypical group, 11 patients (55\%) had centrally located lesions and nine patients (45\%) had peripherally located lesions (Table 1).

According to the results of the USG BI-RADS classification, 24 patients were reported as BI-RADS $4 \mathrm{~A}$, three patients as BI-RADS $4 \mathrm{C}$, two patients as BI-RADS 3, one patient as BI-RADS 4B, and one patient as BI-RADS 5 in the benign group. In the atypical group, 12 patients were reported as BI-RADS 4A, four patients as BI-RADS 4B, three patients as BI-RADS 5, and one patient as BI-RADS 4C (Table 1 ; Figures 1 and 2).

Forty-one patients underwent MMG. Microcalcification was monitored at a rate of $6 \%(2 / 31)$ in the benign group. This rate was higher $(25 \% ; 5 / 20)$ in the atypical group (Table 1$)$.

While the rate of ductal ectasia was $54 \%$ (17/31) in the benign group, it was $6 \%(3 / 20)$ in the atypical group. All three ductal ectasias monitored in the atypical group were centrally located, and their excision diagnoses were intraductal papilloma with DCIS (Table 1).

Eighteen out of 20 patients, who were diagnosed with papillary neoplasia and in whom loss of myoepithelial cell layer was detected as a result of core biopsy, were diagnosed with atypical papillary lesions based on the excision materials. The loss of myoepithelial cell layer was not detected in the biopsy material of the other two patients in the atypical group, and they were diagnosed with intraductal papilloma with DCIS based on the excision materials (upgrade rate was 4\%). Myoepithelial cell layers were continuous in the core biopsies and excision materials of all patients in the benign group.

In only four patients in the benign group, intraductal papilloma was accompanied by atypical ductal hyperplasia in the excision materials. Their mean age was 48 (35-67). In three of the four patients, the lesions were centrally located, while it was peripherally located in one patient. The mean size of the lesions was $13.75 \mathrm{~mm}$. 
In our series, the mean age of patients with papillomas with DCIS $(5 / 51)$ was $50.5 \pm 11.4$ years. The mean size of large lesions was $28.5 \mathrm{~mm}$. Four of the aforementioned five patients had centrally located lesions and one had peripherally located lesions. Four of them were diagnosed as BI-RADS $4 \mathrm{~A}$ and one was diagnosed as BI-RADS 4C. Ductal ectasia was detected in three patients, and microcalcification was detected in two patients. Histopathological images of one of the patients with papilloma with DCIS are shown in Figures 3 and 4.

Core biopsies and ultrasound were performed in 50 patients, while only one patient underwent excisional biopsy. All biopsies were sampled with 16-gage (G) (16 G; 38 patients) or 18-gage (G) (18 G;
13 patients) needles. In our study, the mean size of core-needle biopsy tissue samples was $26 \mathrm{~mm}$ (Table 1).

\section{Discussion and Conclusion}

To date, several studies have been conducted to predict preoperative atypia in papillary breast lesions (2-6). Our study also contributes to the literature as it contains detailed radiological, pathological, and demographic data.

According to studies in literature, lesions located on the left breast and peripherally, advanced age, large-sized lesions, and high BI-RADS category may help predict atypia (6-10).

Table 1. Demographic, pathological, and radiological descriptive findings and statistical value of the groups

\begin{tabular}{|c|c|c|c|c|}
\hline & $\begin{array}{l}\text { All papillary } \\
\text { neoplasms } \\
(n=51)\end{array}$ & $\begin{array}{c}\text { Benign papillary } \\
\text { neoplasms } \\
(n=31)\end{array}$ & $\begin{array}{l}\text { Atypical papillary } \\
\text { neoplasms } \\
(n=20)\end{array}$ & p-value \\
\hline Number & 51 & 31 & 20 & - \\
\hline \multicolumn{5}{|l|}{ Age } \\
\hline Mean \pm SD & 44 & $49.09 \pm 12.31$ & $57.65 \pm 12.82$ & 0.05 \\
\hline$<40$ & 7 & 6 & 1 & \\
\hline$\geq 40$ & 44 & 25 & 19 & \\
\hline \multicolumn{5}{|l|}{ BI-RADS category } \\
\hline 3 & 2 & 2 & 0 & * \\
\hline $4 a$ & 36 & 24 & 12 & \\
\hline $4 b$ & 5 & 1 & 4 & \\
\hline $4 c$ & 4 & 3 & 1 & \\
\hline 5 & 4 & 1 & 3 & \\
\hline \multicolumn{5}{|l|}{ Mass size $(\mathrm{mm})$} \\
\hline Mean \pm SD & $23.2 \pm 19 \mathrm{~mm}$ & $14.2 \pm 0.9 \mathrm{~mm}$ & $31.15 \pm 1.2 \mathrm{~mm}$ & $<0.01$ \\
\hline$<1 \mathrm{~cm}$ & 10 & 10 & 0 & \\
\hline$>1 \mathrm{~cm}$ & 41 & 21 & 20 & \\
\hline Loss of myoepithelial cell layer & 18 & 0 & 18 & $p<0.001$ \\
\hline \multicolumn{5}{|l|}{ Location } \\
\hline Peripheral & 12 & 3 & 9 & * \\
\hline Central & 39 & 28 & 11 & \\
\hline \multicolumn{5}{|l|}{ Lesion laterality } \\
\hline Right & 15 & 10 & 5 & $>0.05$ \\
\hline Left & 36 & 21 & 15 & \\
\hline Microcalcification & 7 & 2 & 5 & * \\
\hline Ductal ectasia & 23 & 17 & 6 & $<0.01$ \\
\hline Needle gage size & 37 & 22 & 15 & * \\
\hline \multicolumn{5}{|l|}{$16 \mathrm{G}$} \\
\hline Needle gage size & 14 & 9 & 5 & * \\
\hline \multicolumn{5}{|l|}{$18 \mathrm{G}$} \\
\hline Core biopsy sample (mean) & $18 \mathrm{~mm}$ & $17 \mathrm{~mm}$ & $17.5 \mathrm{~mm}$ & $>0.05$ \\
\hline
\end{tabular}


In our study, the mean age of the atypical group was 59.4 years $(40$ $79)$, which is higher than that of the benign group, 48 years (23-70). This is consistent with literature data (1).

The mean size of the largest tumor detected on ultrasound was higher in the atypical group $(31.15 \pm 1.2 \mathrm{~mm})$ compared with the benign group $(14.2 \pm 0.9 \mathrm{~mm})$, which is consistent with literature data. No lesion smaller than $1 \mathrm{~cm}$ was detected in the atypical group ( $0 \%$; $0 / 20)$, while $35 \%(11 / 31)$ of the lesions in the benign group were 1 $\mathrm{cm}$ and smaller. In some studies in the literature, lesions larger than 1 $\mathrm{cm}$ were associated with atypia, which agrees with our results $(1,7,8)$.

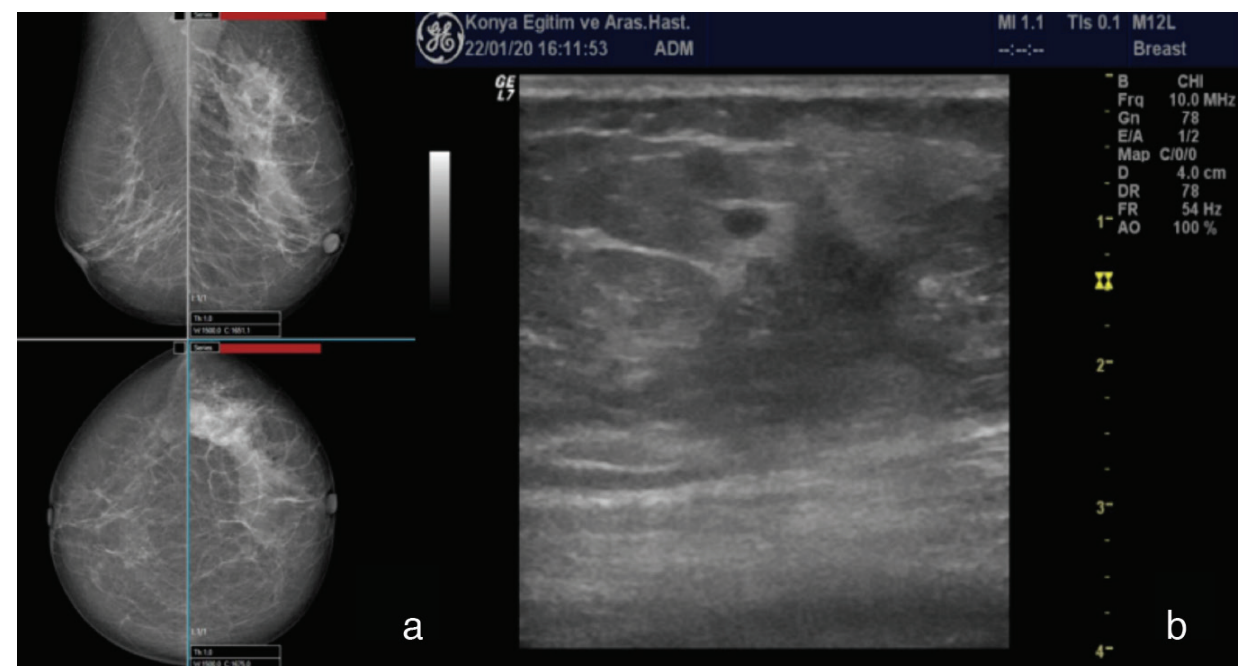

Figure 1. A 64-year-old woman presenting with pain in the left breast. (a) On the mammogram (MMG), there was a global asymmetric density increase in the upper left quadrant of the left breast. (b) On breast ultrasonography (USG), an irregular spiculated contoured mass lesion with a size of $22 \times 16 \mathrm{~mm}$ was detected at a distance of $7 \mathrm{~cm}$ nipple, at 2 o'clock of the left breast. Imaging findings (MMG + USG) were reported as BI-RADS 5. The pathological result of the core biopsy taken from the defined lesion and USG was reported as a papillary neoplasm. The final pathological result of the excision was reported as encapsulated papillary carcinoma

BI-RADS: Breast Imaging Reporting and Database System score
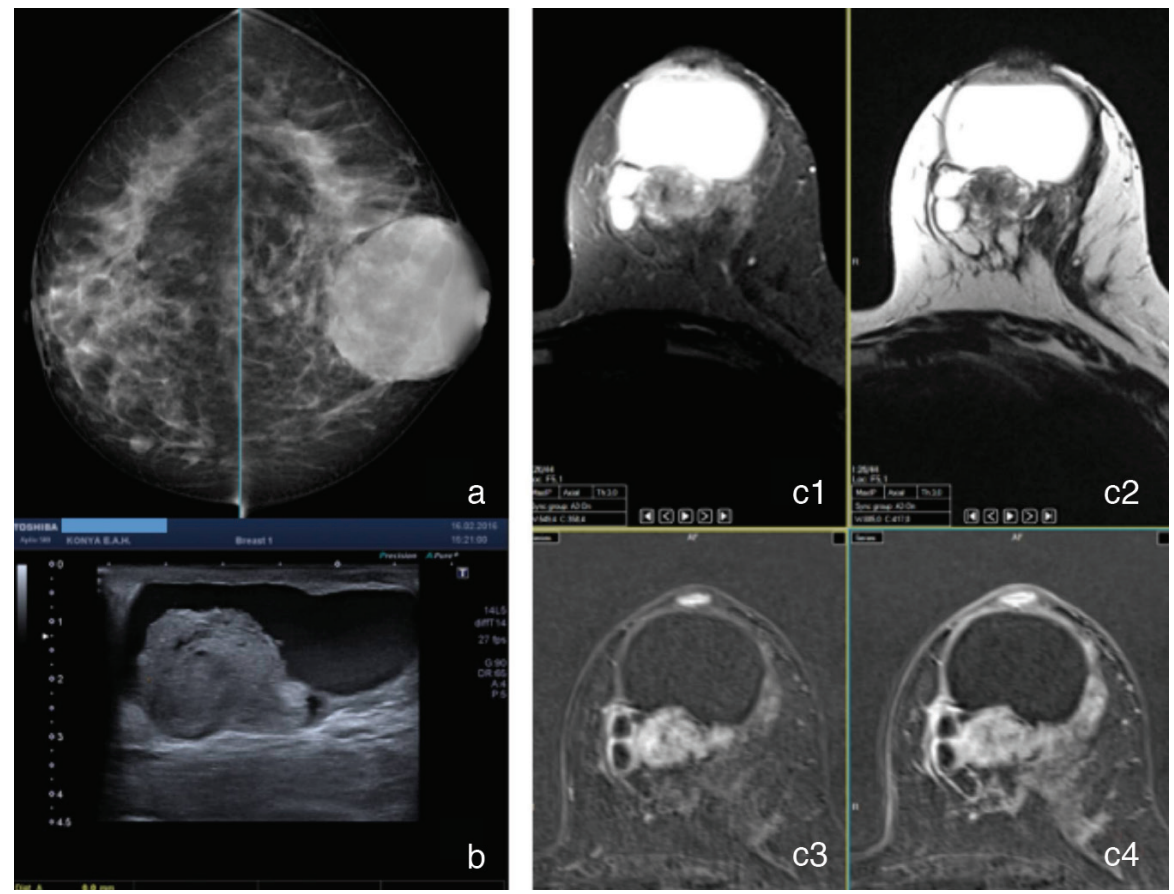

Figure 2. A 45-year-old female patient presenting due to stiffness in the left breast. (a) Increased nodular density increase in left breast retro areolar area on MMG, (b) on the USG, a solid component with dimensions of $24 \times 28 \mathrm{~mm}$ was detected in the posterior wall of the cyst of 65 x $60 \mathrm{~mm}$ in the left breast retroareolar area. In the breast MRI examination, (c1), in the posterior wall of the cyst in the retroareolar area. Isointense with fibroglandular tissue on T1A images. (c2) Mild hyperintense from fibroglandular tissue in T2A images. (c3 and c4) On the contrast dynamic series, a mass lesion showing pathological contrast enhancement in the early phase and drawing a plateau of the contrast curve in the late phase was observed. Imaging findings (MMG + USG + MRI) were reported as BI-RADS 4b. The pathological result of a Tru-Cut biopsy taken from the defined lesion with USG was reported as papillary lesion. As a result of the excision, the final pathological result was reported as intraductal /intracystic papilloma. 
Although studies assert that the BI-RADS category can predict atypical papillary lesions, there was no difference between the two groups in terms of the BI-RADS category according to our study results (4).

When tumor locations were evaluated, it was found in a study in the literature that the rate of peripheral location in the atypical group was $57 \%$, while the rate of central location was $42 \%$ (3). Similarly, these rates were 55\% (11/20) and 45\% (9/20), respectively, in our study. Lesions of only three patients $(10 \%)$ in the benign group were located peripherally, and the rest of the patients $(28 ; 90 \%)$ had centrally located lesions. In such a case, although the peripheral location is relatively higher in atypical lesions, the location of the lesion will not help give a certain result.

Table 2. Results of excision of 51 patients diagnosed with papillary neoplasm as a result of core biopsy

\section{Atypical papillary lesions}

$\begin{array}{ll}\text { Encapsulated papillary carcinoma } & 4 \\ \text { Invasive encapsulated papillary carcinoma } & 1 \\ \text { Invasive papillary carcinoma } & 5 \\ \text { Solid papillary carcinoma } & 2 \\ \text { Papillary DCIS } & 3 \\ \text { Intraductal papilloma with DCIS } & 5 \\ \text { Total } & 20\end{array}$

\section{Benign papillary lesions}

\section{Intraductal papilloma}

Intraductal papilloma with atypical ductal hyperplasia

Total

DCIS: Ductal carcinoma in situ

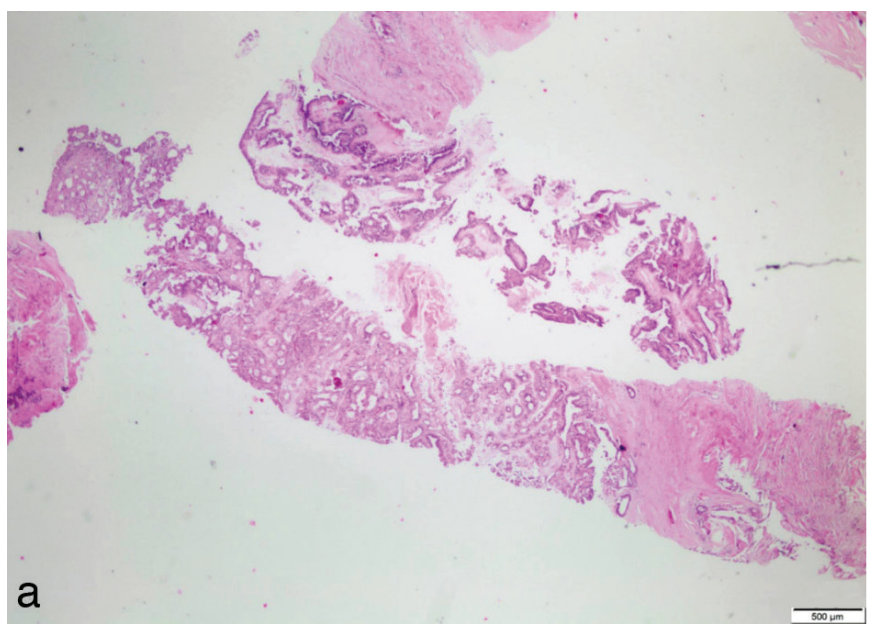

Microcalcification was detected in two patients $(6 \%)$ in the benign group and five patients (20\%) in the atypical group. Although the rate of microcalcification was relatively higher in the atypical group in our study, studies in the literature did not find MMG results reliable for papillary lesions (10).

In our study, the mean size of lesions was $21 \mathrm{~mm}$, the mean size of core biopsy samples was $17.2 \mathrm{~mm}$, and mean sample length per $\mathrm{cm}$ calculated as $8 \mathrm{~mm}$, which resulted in a low upgrade rate (4\%). We recommend collecting at least a $1 \mathrm{~cm}$ sample per lesion size in papillary lesions since this increases diagnostic sensitivity and decreases the upgrade rate. Therefore, the clinician must check if the lesion is adequately sampled before the decision of excision or follow-up is made.

In core biopsies, the myoepithelial cell layer was regular in all benign lesions. There was a partial or complete loss of myoepithelial cell layer in all atypical lesions except for two patients whose lesions were associated with an upgrade (Figures 3 and 4). Our findings were consistent with literature data $(1,7,11,12)$.

Although heterogeneity in papillary lesions is still a source of concern, comprehensive studies generally show low upgrade rates. A large number of studies were conducted on the increase in the histopathological degree of the lesion in excision material after core biopsy, which is defined as an upgrade. In recent literature, intraductal papilloma has an incidence of upgrade ranging from $0 \%$ to $16 \%(5,12$, 13). According to our results, the upgrade rate was $4 \%(2 / 51)$, which is consistent with literature data. The excision diagnosis of two papillary lesions that were upgraded was intraductal papilloma with DCIS. In core biopsy material of papillary neoplasia, where the myoepithelial cell layer is regular and cytological atypia is not observed, papilloma with DCIS can be missed due to the heterogeneity of the lesion.

In our series, the loss of the myoepithelial cell layer was the most significant parameter in predicting atypical papillary lesions. Apocrine cells are more common in benign papillomas that were associated with the loss of myoepithelial cell, which may be misleading in that case. In

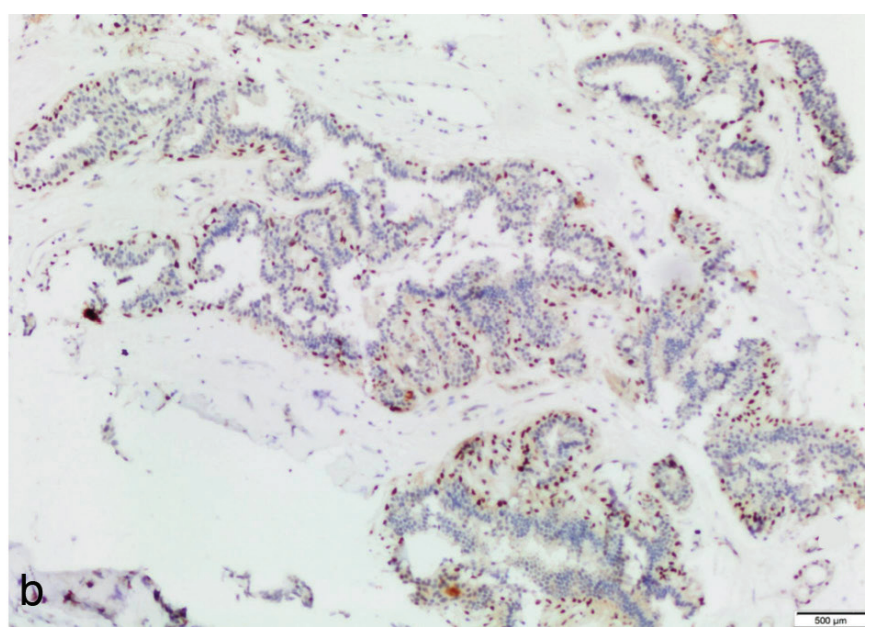

Figure 3. A 40-year-old female patient with a $3.5 \mathrm{~cm}$ diameter mass presented with pain in the left breast. Imaging findings (MMG + USG + MRI) were reported as BI-RADS 4a. The pathological result of a Tru-Cut biopsy taken from the defined lesion with USG was reported as papillary neoplasm. (a) In the core biopsy sample, the papillary neoplasm was diagnosed (H\&E; 20x). (b) The myoepithelial layers are shown regularly with $p$ 63. As a result of the excision, the final pathological result was reported as intraductal papilloma with DCIS (one of our patients whose lesion was associated with an upgrade) 

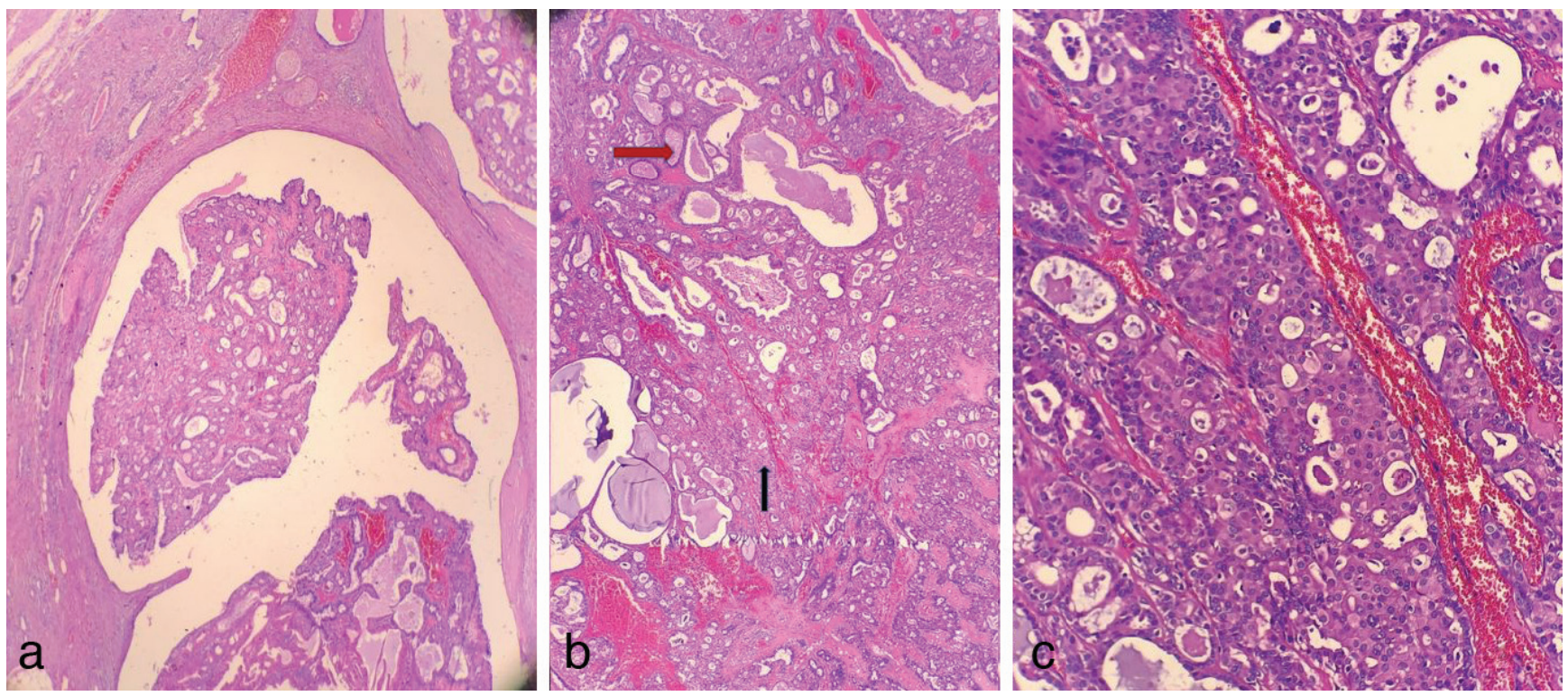

Figure 4. Histopathological images of the excision material of patient with intraductal papilloma with DCIS. The core biopsy sample of this patient is shown in Figure 3. (a) Benign areas of lesion (H\&E; 40x). (b) Benign/intraductal papilloma and atypical/ductal carcinoma in situ areas of the lesion (H\&E; 40x). (c) Higher magnification of DCIS areas of the intraductal papilloma (H\&E; 400x)

H\&E: Hematoxylin and eosin; DCIS: Ductal carcinoma in situ

such cases, the absence or extremely rare presence of mitosis in benign papillomas will be a clue for us (1).

According to our findings, papillary lesions must be excised if loss of myoepithelial cell layer was detected as a result of core biopsy, which is consistent with literature data (1). If the myoepithelial cell layer is the regular size of the lesion and the size of the sample should be assessed and the lesion's other parts that cannot be represented on core biopsy should be considered in that case. If the size of the lesion is larger than $1 \mathrm{~cm}$ (lesion size was larger than $3 \mathrm{~cm}$ in two patients whose lesions were associated with an upgrade) and patient is older than 40 years, new samples or excision may be recommended. If the lesion size is smaller than $1 \mathrm{~cm}$ and the patient is young and does not want an operation, a close follow-up is recommended.

According to our results, although lesion size, advanced patient's age, and loss of myoepithelial cell layer can guide us, taking a $1 \mathrm{~cm}$ sample per $\mathrm{cm}$ of tumor size will decrease the possibility of histopathological upgrade. In radiological studies, defining suspected areas of papillomas with DCIS and focusing on sampling from these areas may help decrease the upgrade rates.

We recommend that when encountering a core biopsy sample of a papillary lesion without significant cytological atypia and malignancy, it should be reported as papillary neoplasia with regular myoepithelial cell layer or focal/complete loss of the myoepithelial cell layer.

As our study included many radiological and histopathological data, it can guide breast surgeons, radiologists, and pathologists in clinical practice in terms of papillary neoplasms.

Ethics Committee Approval: The Local Ethics Committee of Konya Training and Research Hospital (decision no: 48929119/774, date: 02.07.2020) approved this study.
Informed Consent: Written informed consent was obtained from patients who participated in this study.

Peer-review: Externally peer-reviewed.

\section{Authorship Contributions}

Conception: A.N.U.K., Z.B.; Design: A.N.U.K., Z.B., A.A.; Supervision: Y.Ü., M.A.E.; Resources: A.N.U.K., N.B.; Materials: A.N.U.K., Z.B.; Data Collection and/or Processing: A.N.U.K., N.B., A.A.; Analysis and Interpretation: A.N.U.K., Z.B.; Literature Search: Y.Ü., N.B.; Writing: A.N.U.K., Z.B., N.A., E.N.Ö.Y.; Critical Review: N.A., M.A.E.

Conflict of Interest: The authors have no conflicts of interest to declare.

Financial Disclosure: The authors declare that this study received no financial support.

\section{References}

1. Brogi E, Horii R, Mac Grogan G, Rakha EA, Troxelli ML, Tse G, et al. Papillary neoplasms: breast tumours, WHO classification of tumours. $5^{\text {th }}$ ed. WHO Classification Editorial Board, 2019: 49. [Crossref]

2. Cheng TY, Chen CM, Lee MY, Lin KJ, Hung CF, Yang PS, et al. Risk factors associated with conversion from nonmalignant to malignant diagnosis after surgical excision of breast papillary lesions. Ann Surg Oncol. 2009; 16: 3375-3379. (PMID: 19641969) [Crossref]

3. Rizzo M, Linebarger J, Lowe MC, Pan L, Gabram SG, Vasquez L, et al. Management of papillary breast lesions diagnosed on core-needle biopsy: clinical pathologic and radiologic analysis of 276 cases with surgical followup. Jx Am Coll Surg 2012; 214: 280-287. (PMID: 22244207) [Crossref]

4. Youk JH, Kim EK, Kwak JY, Son EJ, Park BW, Kim SI. Benign papilloma without atypia diagnosed at US-guided 14-gauge core-needle biopsy: clinical and US features predictive of upgrade to malignancy. Radiology 2011; 258: 81-88. (PMID: 20971773) [Crossref]

5. Wen X, Cheng W. Nonmalignant breast papillary lesions at core-needle biopsy: a meta-analysis of underestimation and influencing factors. Ann Surg Oncol 2013; 20: 94-101. (PMID: 22878621) [Crossref] 
6. Nayak A, Carkaci S, Gilcrease MZ, Liu P, Middleton LP, Bassett Jr RL, et al. Benign papillomas without atypia diagnosed on core needle biopsy: experience from a single institution and proposed criteria for excision. Clin Breast Cancer 2013; 13: 439-449. (PMID: 24119786 [Crossref]

7. Hong YR, Song BJ, Jung SS, Kang BJ, Kim SH, Chae BJ. Predictive factors for upgrading patients with benign breast papillary lesions using a core needle biopsy. J Breast Cancer 2016; 19: 410-416. (PMID: 28053629) [Crossref]

8. Wiratkapun C, Keeratitragoon T, Lertsithichai P, Chanplakorn N. Upgrading rate of papillary breast lesions diagnosed by core-needle biopsy. Diagn Interv Radiol 2013; 19: 371-376. (PMID: 23748032) [Crossref]

9. Agoff SN, Lawton TJ. Papillary lesions of the breast with and without atypical ductal hyperplasia: can we accurately predict benign behavior from core needle biopsy? Am J Clin Pathol 2004; 122: 440-443. (PMID: 15362376) [Crossref]
10. Pathmanathan N, Albertini AF, Provan PJ, Milliken JS, Salisbury EL, Bilous AM, et al. Diagnostic evaluation of papillary lesions of the breast on core biopsy. Mod Pathol 2010; 23: 1021-1028. (PMID: 20473278) [Crossref]

11. Yang Y, Suzuki K, Abe E, Li C, Uno M, Akiyama F, et al. The significance of combined CK5/6 and p63 immunohistochemistry in predicting the risks of subsequent carcinoma development in intraductal papilloma of the breast. Pathol Int 2015; 65: 81-88. (PMID: 25572436) [Crossref]

12. Grimm LJ, Bookhout CE, Bentley RC, Jordan SG, Lawton TJ. Concordant, non-atypical breast papillomas do not require surgical excision: a 10-year multi-institution study and review of the literature. Clin Imaging 2018; 51: 180-185. (PMID: 29859481) [Crossref]

13. Pareja F, Corben AD, Brennan SB, Murray MP, Bowser ZL, Jakate K, et al. Breast intraductal papillomas without atypia in radiologic-pathologic concordant core-needle biopsies: Rate of the upgrade to carcinoma at excision. Cancer 2016; 122: 2819-2827. (PMID: 27315013) [Crossref] 